\title{
Implementation of Wireless Sensor Networks to Prevent Deforestation Using Node MCU
}

\author{
Sivasankari $\mathrm{N}^{\mathrm{a}, 1}$, Mounika $\mathrm{S} \mathrm{C}^{\mathrm{b}}$ and PriyaDharshini $\mathrm{K}^{\mathrm{b}}$ \\ a Asst Prof, Mepco Schlenk Engineering College, Sivakasi \\ ${ }^{\mathrm{b}}$ UG Scholar, Dep of ECE, Mepco Schlenk Engineering College, Sivakasi
}

\begin{abstract}
The illegal movement of valuable trees such as sandal wood trees in forests poses a severe risk to natural reserves and it instigates a great loss to our country's wealth. Almost 24,000 square miles has been lost due to deforestation in the past decade. This paper proposes an antipoaching system using NodeMCU based wireless system that uses 3- axis MEMS accelerometer (GY-61) and tilt sensor for detecting the falling of trees due to cutting of trees or natural calamities and Flame sensor, fire retardant for detecting and controlling the fire. In this project we use NodeMCU which has an inbuilt Wi-Fi module which covers a distance of around $300 \mathrm{~m}$ range, is used in this project for cost efficiency and also NodeMCU enables the communication with neighbor nodes like client and server nodes. This protocol is used to monitor the trees even using a single node from the server system. The solenoid valve is used to spray the fire retardant to control the fire. Some IOT modules can also be used in this system to provide accurate information and remote monitoring of trees.
\end{abstract}

Keywords. NodeMCU, Flame sensor, Tilt Sensor, 3- axis MEMS accelerometer.

\section{Overview:}

At the present time smuggling or plundering of economically important species in forest areas such as Teakwood, Sandalwood, Pine and Rosewood has been intensely enlarged. Several measures started by different sponsors and Government of India, to reduce these problems. In earlier days, trees are protected by trained watchmen and forest officials. Later on, they employed CCTV cameras and send the feed images to the server room to examine to avoid the smuggling and control the forest fire, due to their high cost most of the cameras are stolen by the people. Also, Strict penalties for convicted offenders, as well as giving special incentives for anti-poaching activities (12 ${ }^{\text {th }}$ Five Year Plan 2012-2017) were aimed for destroying the menace. However, the corrective measures have remained largely ineffective, but still poachers continue to thrive. The most effective solution is the employment of a wireless sensor network in forest which will be advanced and a cheap modern technology to make monitoring more robust, effective and feasible.

\section{Existing System}

Naveen Raj et. al[1] proposes the IoT based Anti-Poaching Alarm System for Trees in 
Forest. They proposed anti-poaching alarm system is used to frame the core of the framework.In that all the sensor hubs are associated with the controller unit. Sensor information is prepared in the microcontroller and transmit it to the collector unit to enable recipient unit to judge

Whether the ecological conditions prompts woods fire or not. Here they use tilt sensor as a segment of the project that can identify the tilting of a target object similar to a push button. Temperature sensor is a major equipment which contains thermometers, restriction temperature locators and thermocouples and the sound sensor module provides a basic strategy to perceive sound and is normally used for recognizing sound power. It uses a mouthpiece which supplies the commitment to a speaker, top marker and support. Thus, this provides a system to detect poaching activities.

Smita Gaikwad et. al[2] proposed the Design of WSN Node For Protection Of Forest Trees Against Poaching Based MSP430. Wireless Sensor Networks (WSNs) technology, which consists of sensing theft by monitoring the output produced by the tilting of trees using a 3-axis accelerometer. A low power MSP430 microcontroller is used with RF modules.

Xhevahir Bajrami et. al[3] proposed an efficient approach to monitoring environmental conditions using a wireless sensor network and NodeMCU. In this project they suggested a method to create a wireless sensor networks to check the environmental changes inside a laboratory. They used NodeMCU to transmit sensor values via Wi-Fi. They have created Web API for web applications. The cloud-based database is maintained for storing and analyzing the sensor values. The extreme environmental conditions were notified by the mobile.

From the above systems we came to know that existing system consists of a microcontroller based antipoaching system which uses WSN. The system consists of sensors [7] for avoiding the deforestation caused by the cutting/falling of trees. It also uses low power msp430 and zigbee modules along with RF modules for long distance coverage. Though RF modules covers a long distance the cost is high compared to other modules.

\section{Proposed System}

The proposed system uses NodeMCU (ESP8266) which has inbuilt Wi-Fi module and the sensors 3- axis accelerometer (GY-61 and ADXL337) and tilt sensor for detecting the vibration of trees in $\mathrm{x}, \mathrm{y}$ and $\mathrm{z}$ - axis and Flame sensor for the detection of forest fire. In our system fire retardant has been used to control the spreading of fire and solenoid valves are used to spray the fire retardant. The NodeMCU along with multiplexer IC741 supports eight analog sensors at the same time using the data pins of the mux with the help of the select lines. Our system has the ability to send notifications to the mobile phones of the authorities using the BLYNK app simultaneously. Nodes can be easily monitored remotely with their smart phones and appropriate nodes can be found accordingly.

\subsection{Flow Chart}

The wireless sensor network consists of sensor units where each unit consists of two sensors, a flame sensor and a tilt sensor or accelerometer sensor. One sensor unit act as 
a main server which sends the sensed data to the solenoid valve to control the fire retardant and also sends the notification to the authorities. All the other sensor units act as client nodes which transmit the data to the main server node. From this main node, the solenoid valve gets the data to control the fire in the forest areas depending upon the sensor values. The sensor unit senses the environment in a periodic interval and conveys the information.

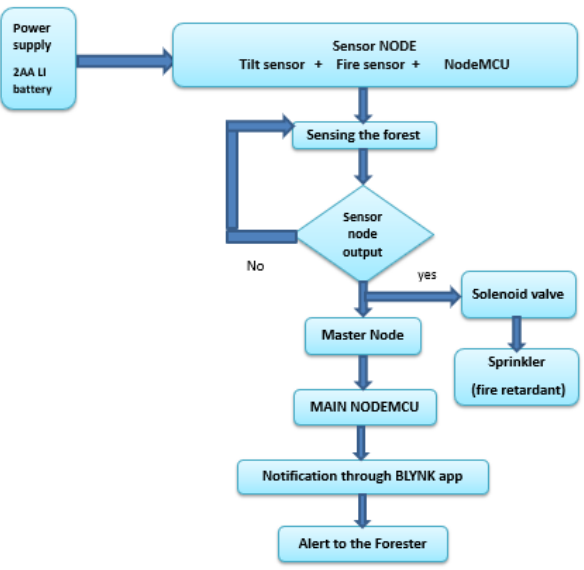

Figure 1. Flow Chart of Proposed Architecture

\subsection{Components used}

\subsubsection{NodeMCU (ESP8266)}

It is a Microcontroller with integrated Wi-Fi. It is of Physical size $49 \times 24.5 \times 13 \mathrm{~mm}$ and consumes 0.00026 to $0.56 \mathrm{~W}$ of power. It has a port to integrate with the computer using the USB cable. The NodeMCU is not always in the ON state, data values are noted periodically, which means that the power consumption is drastically lowered. NodeMCU is a device with integrated Wi-Fi which can be used to make our own soft access point with SSID and password. The soft access point of one NodeMCU can be connected with other NodeMCU's soft access point for communication of the wireless nodes. NodeMCU itself can generate its own Wi-Fi when powered up where the other microcontrollers can't generate on its own.

\subsubsection{Sensor Unit (Single Node)}

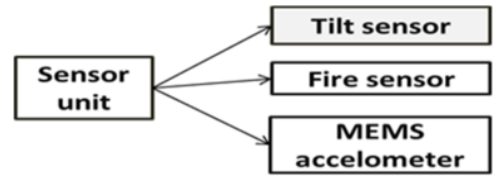

Figure 2. Sensor Unit 


\subsubsection{ADXL335 / GY-61 vibration sensor}

ADXL335 is a 3-axis accelerometer and its selectable measurement range is of $\pm 3 \mathrm{~g}$. This ADXL335 is interfaced with NodeMCU through the analog pin A0. The ADXL335 is a small, thin, low power 3 -axis accelerometer with the signal influenced voltage outputs. The user can detect the axes of tilt along the $\mathrm{x}, \mathrm{y}$ and $\mathrm{z}$ directions. This sensor measures the acceleration with a full-scale range of $+/-3 \mathrm{~g}$.

\subsubsection{Flame sensor}

Flame sensor is used to detect the fire which is very much efficient than heat and gas sensors, the analog value for fire ranges in between 20-90 and above 100 is considered as detection of absence of fire.

\subsubsection{Tilt sensor}

A tilt sensor is a sensor to measure the tilt in multiple axes of a reference plane. Tilt sensors measure the tilting position with reference to gravity which are used in many applications. This instrument is used to detect the orientation and inclination.

\subsubsection{Solenoid Valve}

A solenoid valve is an electromechanically operated valve. Solenoid valves are classified based on the current used, the strength of the magnetic field generated, the mechanism they use to regulate the fluid, and the type and characteristics of fluid they control. In this system the sensor data is sent to the input pin which makes the solenoid valve open and through this opening the fire retardant is sprayed to the fire areas.

\subsection{Diagram}

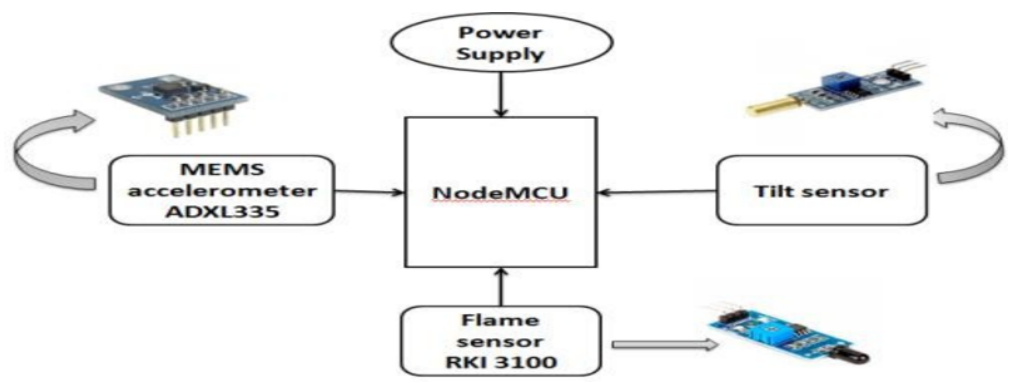

Figure 3. Block Diagram of a single node

In the sensor unit, the NodeMCU is connected to two sensors MEMS accelerometer/ tilt sensor for the detection of fall of the trees and flame sensor for the detection of fire in the forest. Power supply is provided to the NodeMCU by 7.4V Lipo battery.In the system the NodeMCU is used which has its own Wi-Fi to transmit the data from the forest areas. The client nodes send the data to the main NodeMCU from which it is transmitted to the solenoid valve to control the flow of fire retardant to the detected 
fire areas. The main NodeMCU will also send notification to the mobile phones of authorities using BLYNK app.

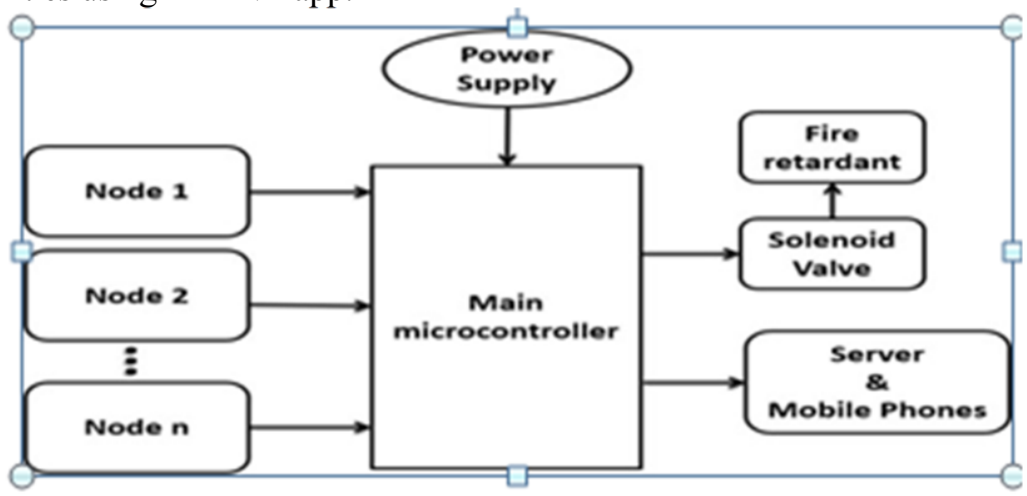

Figure 4. Block Diagram of the sensor network

\subsection{Proposed Architecture}

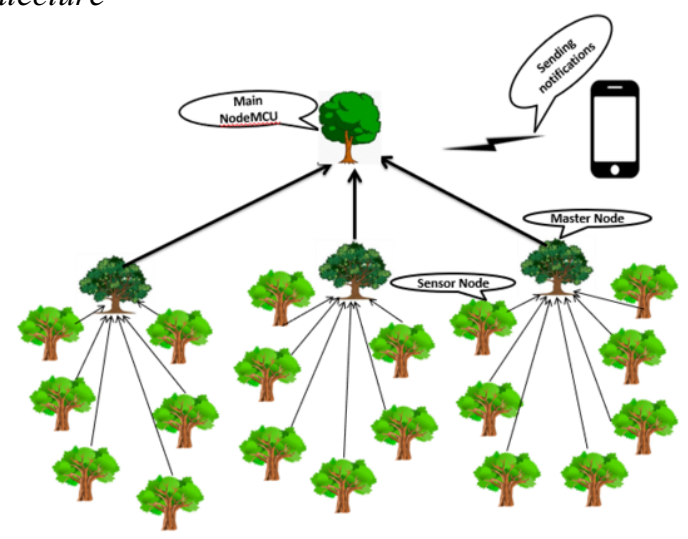

Figure 5. Proposed Architecture of WSN system

\section{Experimentation and Result}

The system has been designed using the NodeMCU and sensors to provide cost efficient system to prevent deforestation. We have tested up to five nodes which can communicate within50 meters among themselves. The nodes will pass the information via Wi-Fi till it reaches the master node. The master node will send notification to the mobile of authorities. The results have been obtained as below. 


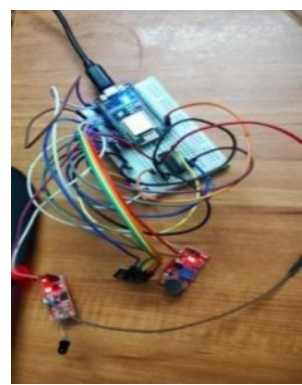

Figure 6. Prototype Module of a single sensor unit

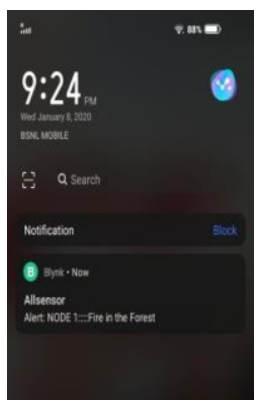

Figure 7. Notification of deforestation activities in Mobile for node 1

The NodeMCU can communicate up to $300 \mathrm{~m}$ but only if it is in line of sight. To avoid that problem we use multiple nodes.

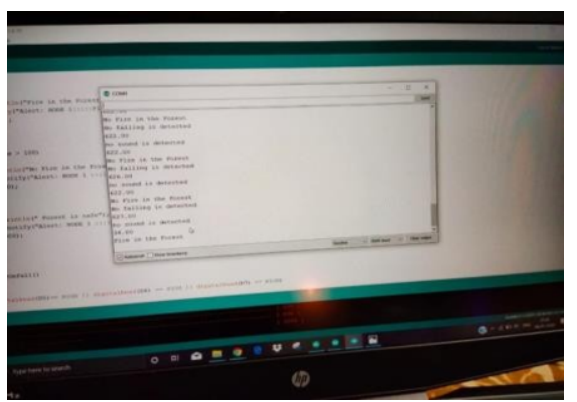

Figure 8. Notification of deforestation activities in Serial Monitor

\section{Conclusion}

In this project, it has been proven that system protects the private farming place such as teak farming, sandalwood farming and it reduces the human guard, always guarding the area for long time. The system involves simple sensors like ADXL 335, Flame sensor and Tilt sensor. These sensor data are sent to main microcontroller from every single node. The concept of IOT is implemented to make the monitoring efficient. The regular updates can be provided to the users through Wi-Fi module (ESP8266). Then, the alerts can be sent to the users through BLYNK app to the authenticated users when suspicious activity is notified. The main motto of this project is to provide cost efficient and reliable monitoring of trees with help of NodeMCU which provides own Wi-Fi service based on wireless technology though there is no network connection in the forests.

\section{References}

[1] Naveenraj M, Arunprasath, Jeevabarathi C.T, Srinivasan.IoT Based Anti-Poaching Alarm System for Trees in Forest. International Journal of Innovative Technology and Exploring Engineering IJITEE. April 2019.ISSN: 2278-3075. Volume-8 Issue-6S.

[2] X. Bajrami, I. Murturi.An efficient approach to monitoring environmental conditions using a wireless sensor network and NodeMCU“ published by Elektrotechnik \& Informationstechnik 2018. 135/3: 294301. https://doi.org/10.1007/s00502-018-0612-9.

[3] Lamir Shkurti,Besim Limani, Xhevahir Bajrami,Samedin Krrabaj ,Astrit Hulaj.Development of Ambient Environmental Monitoring System ThroughWireless Sensor Network WSN Using NodeMCU and WSN Monitoring on 2017 6th Mediterranean conference on embedded computing (MECO), june 
2017, bar, montenegro.11-15 .

[4] Jin Zhao, Xiaoqin Lian, Yelan Wu, Xiaoli Zhang, and Song Wang.Design of Wireless Temperature and Humidity Data Collection System Based on MSP430 and CC2530 published on 2017 3rd International Conference on System Science, Engineering Design and Manufacturing Informatization.

[5] Prof.P.G.Salunkhe,PoonamU.Chaudhari .Design WSN Node For Protection Of Forest Trees Against Poaching Based MSP430 2018 International Conference On Advances in Communication and Computing Technology (ICACCT) Amrutvahini College of Engineering, Sangamner, Ahmednagar, India. 2018 .Feb 8-9.

[6] V.D.Ambeth Kumar (2017).Efficient Routing for Low Rate Wireless Network a Novel Approach.International Journal of Image Mining, 2017.Vol. 2, Nos. $3 / 4$.

[7] V. D. Ambeth Kumar,S. Malathi,Abhishek Kumar,Prakash M and Kalyana C. Veluvolu, "Active Volume Control in Smart Phones Based on User Activity and Ambient Noise",Sensors 2020, 20(15), 4117; https://doi.org/10.3390/s20154117 